WIDER Working Paper 2014/047

\title{
The economics of malaria in Africa
}

Jean-Claude Berthélemy, ${ }^{1,2}$ Josselin Thuilliez ${ }^{1}$

February 2014 
Abstract: Malaria still claims a heavy human and economic toll, specifically in sub-Saharan Africa. Even though the causality between malaria and poverty is presumably bi-directional, malaria plays a role in the economic difficulties of the region. This article provides an analysis of the economic consequences of malaria (with an emphasis on human capital accumulation and productivity), and a discussion of policies aimed at reducing its incidence. A major initiative has been the distribution of insecticidal bed-nets at a highly subsidized price. An economicepidemiology model is used to explain why such policy is doomed to fail in presence of a very high poverty incidence, as observed in the African region.

Keywords: malaria, poverty, economic epidemiology

JEL classification: O12, I15, I25

Acknowledgements: We would like to thank Célestin Monga, Justin Yifu Lin, Ogobara Doumbo, Jean Gaudart, meeting participants of the contributors to the 'Handbook of Africa and Economics', in Beijing, China, as well as UNU-WIDER. This work benefited from the support of FERDI and the French National Research Agency, as part of the programme 'Investissements d'avenir' (ANR-10-LABX-14-01). The authors remain solely responsible for any errors.

1 Centre d'économie de la Sorbonne, CNRS-Université Paris; ${ }^{2}$ FERDI, Fondation pour les Etudes et la Recherche sur le Développement International; Jean-Claude.Berthelemy@univ-paris1.fr ; Josselin.Thuilliez@univ-paris1.fr

This paper was prepared for the 'Oxford Handbook of Africa and Economics' authors' conference in Beijing, 8-10 December 2013, implemented with UNU-WIDER.

Copyright (C) UNU-WIDER 2014

ISSN 1798-7237 ISBN 978-92-9230-768-4

Typescript prepared by Anna-Mari Vesterinen at UNU-WIDER.

UNU-WIDER gratefully acknowledges the financial contributions to the research programme from the governments of Denmark, Finland, Sweden, and the United Kingdom.

The World Institute for Development Economics Research (WIDER) was established by the United Nations University (UNU) as its first research and training centre and started work in Helsinki, Finland in 1985. The Institute undertakes applied research and policy analysis on structural changes affecting the developing and transitional economies, provides a forum for the advocacy of policies leading to robust, equitable and environmentally sustainable growth, and promotes capacity strengthening and training in the field of economic and social policy-making. Work is carried out by staff researchers and visiting scholars in Helsinki and through networks of collaborating scholars and institutions around the world.

UNU-WIDER, Katajanokanlaituri 6 B, 00160 Helsinki, Finland, wider.unu.edu

The views expressed in this publication are those of the author(s). Publication does not imply endorsement by the Institute or the United Nations University, nor by the programme/project sponsors, of any of the views expressed. 
Malaria is prevalent throughout most of the tropical world. In 2010, approximately 2.57 billion people lived in regions of the world at risk of $P$. falciparum transmission (798.42 million in Africa, Gething et al. 2011) and 2.85 billion people were exposed to some risk of $P$. vivax transmission in 2009 (98 million in Africa, Guerra et al. 2010). There were an estimated 1,238,000 million malaria deaths worldwide in 2010 (1,133,000 in Africa, Murray et al. 2012). Malaria is considered one of the most common infectious diseases and the most influential of the parasitic diseases. 1 Furthermore, there is currently no vaccine against the parasite.

Malaria is also more than merely a tropical disease that claims a heavy toll on lives in sub-Saharan Africa (SSA) and is economically costly. In recent debates among development economists, malaria has been at the center of a controversy about the causality between health and economic performances. This relation is probably bidirectional but economic analyses on the cost of malaria in Africa have contributed to this important debate.

In the context of Millennium Development Goals (MDGs), major efforts have been devoted to the fight against malaria. A variety of prevention and treatment measures have been put in place. The cost effectiveness of malaria prevention and treatment tools that have been used in malaria control strategies are in principle very high in experimental contexts. However, large-scale results of impact evaluations of anti-malaria campaigns are not always as positive as they might be. Malaria continues to be a significant cause of global mortality and morbidity. Indeed, despite the recent decreasing trend in malaria mortality and morbidity in Africa and a renewed optimism, it is still difficult to disentangle the complementary causal effects of existing strategies: net distribution; distribution of new antimalarial drugs - artemisinin combination therapies (ACTs); and insecticide spraying.

Numerous examples could be given and are illustrative. First, in spite of massive efforts to generalize efficient prevention, such as insecticide-treated mosquito nets (ITNs) or long-lasting insecticidal nets (LLINs), ITN coverage remains low in large populations at risk despite rapid increase, and ITN are still only used to a limited extent (Flaxman et al. 2010). A second example resides in the controverted results of the Affordable Medicines Facility-malaria (AMFm) programme, a sustained global subsidy of ACTs (Arrow 2004). A last example is related to national malaria control programmes' official policies and results. Van Eijk et al. (2011) synthesise data from national surveys and conclude that coverage of ITNs and intermittent preventive treatment (IPT) in pregnant African women is inadequate despite the fact that 45 of the 47 countries surveyed had a policy for distribution of ITNs for pregnant women and 39 had an intermittent preventive treatment policy. These results suggest a need for a deeper economic analysis combined with epidemiological tools that recognizes the complex character of malaria. This is all the more feasible in 2013, contrary to 10 years ago, because part of the information

\footnotetext{
${ }^{1}$ Most of infections in humans are caused by four different species of the genus Plasmodium. Plasmodium falciparum, Plasmodium malariae, Plasmodium vivax, and Plasmodium ovale are associated with different clinical presentations, progression, prevalence, and antimalarial resistance patterns. Recently human malaria cases due to $P$. knowlesi have been detected (Singh and Daneshvar 2013). P. falciparum infection results in the highest morbidity and mortality, accounting for almost all of the over one million deaths caused by malaria annually, most of them in young children in Africa. The incidence of malaria is defined as the number of new cases of malaria for a given population during a specific time period (given in person-time). The prevalence of malaria is defined as the total number of malaria cases in a given population at a specific time.
} 
gap on malaria morbidity could be filled with the growing number of large scale malaria indicator surveys.

In addition, the analysis of Arrow (2004) suggests that insecticide-treated bed nets and other, broad environmental strategies offer great potential for synergy when effective drug therapies are available'. Indeed, it would be necessary to identify the optimal combination of strategies for action in an integrated way, given the risk of development of ACT-resistant Plasmodium falciparum malaria parasites

This paper is organized as follows: The next section provides a description of malaria control strategies that have been implemented in Africa. Section 3 gives an overview of economic methods used for estimating the economic impact of Malaria in Africa and estimating malaria costs, taking into account the endogenous relationship between malaria and economic development. Section 4 presents a malaria economic epidemiology model, aiming at explaining why under some circumstances policies of dissemination of protection devices cannot eradicate malaria; such circumstances are in particular related to situations where the poverty incidence is high. Section 5 concludes.

\section{Malaria control strategies in Africa: an overview}

\subsection{Recent history of malaria control in Africa}

Figure 1 provides a very schematic history of malaria control since 1900. There is evidence that the World Health Organization (WHO) global initiative to fight malaria launched in the 1950s has been much more effective in Asia than in Africa. The emergence and spread of chloroquineresistant Plasmodium falciparum malaria parasites has been a disaster for world health. This figure is obviously schematic and Murray et al. (2012) have shown that past estimates provided for malaria cases and deaths were probably underestimated, but it is however informative.

The first worldwide eradication programme was launched by the WHO in 1955. The programme was based on house spraying with residual insecticides, antimalarial drug treatment, and surveillance. However, the most malarious areas, such as tropical Africa, were excluded due to overwhelming difficulties (Alilio et al. 2004). ${ }^{2}$ Newly independent states in tropical Africa were thus relying on marginal sponsored actions (residual insecticide spraying in a few urban centers, or larviciding in limited areas), national health systems and national malaria control programmes already operational by the 1950s, hospitals and dispensaries-based antimalarial activities, mass drug administration and availability of antimalarial drugs in the open market. The extensive use of residual insecticide dichloro-diphenyl-trichloroethane (DDT) and chloroquine (CQ) ${ }^{3}$ did benefit to Africa as overall malaria-related deaths in Africa showed evidence of decline from the 1950s to 1980s. However, these activities may have promoted the development of both drug and insecticide resistance.

\footnotetext{
2 A full history of malaria control programmes in Africa can be found in Carter and Mendis (2002) and Alilio et al. (2004).

${ }^{3}$ A drug used for the treatment and prevention of malaria, discovered in 1934 and established as an effective and safe antimalarial in 1946.
} 


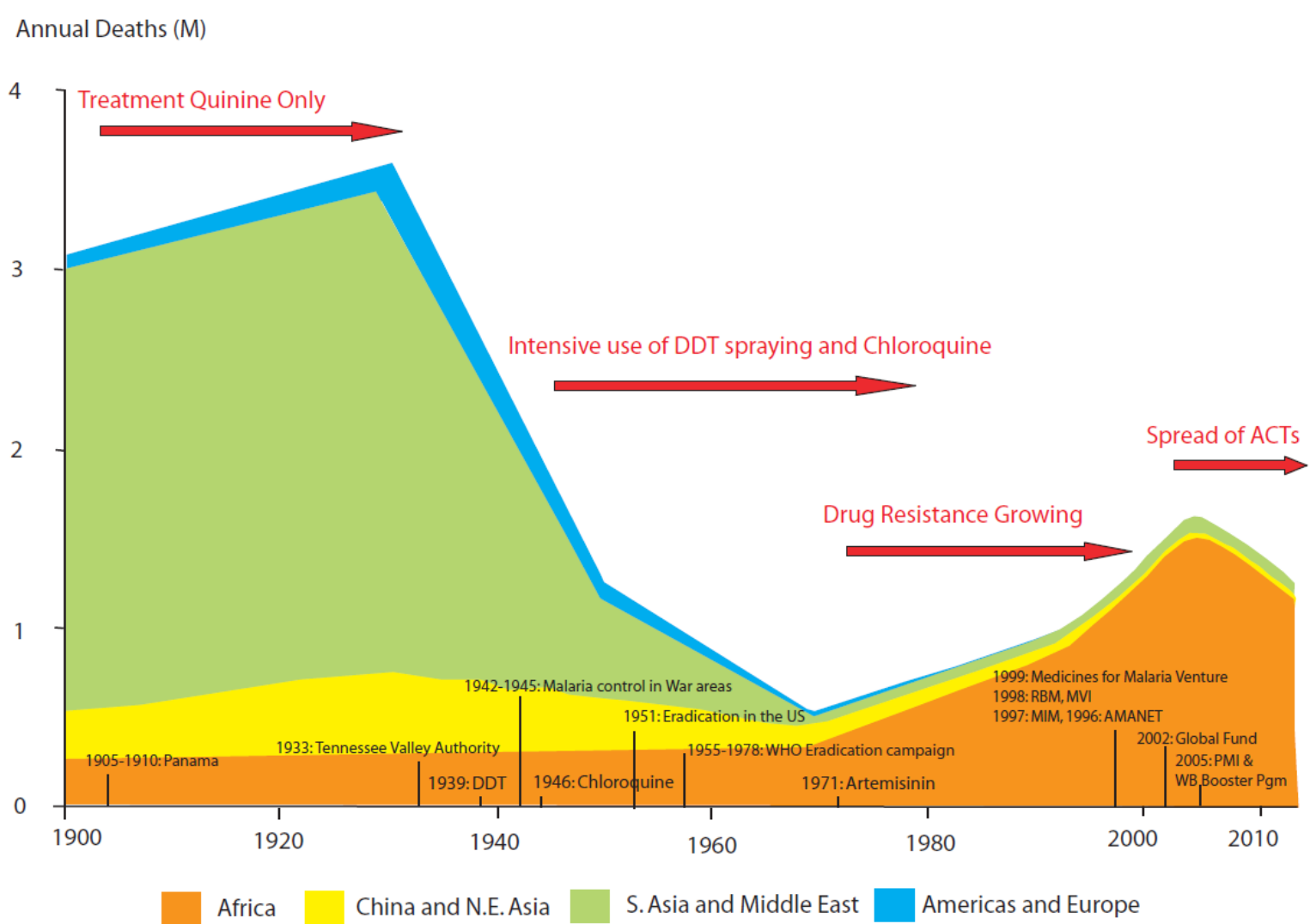

Source: Authors, based on Carter and Mendis (2002); Alilio et al. (2004); Murray et al. (2012); and RBM (2013).

Indeed, the downward trend in malaria-related mortality appears to have reversed in the 1970s due to CQ resistance and the small effect of residual insecticide DDT in SSA. Conversely, Asian malaria transmission was much more sensible to vector control measures using DDT because of the lower intensity of this transmission, a relative organizational and political stability after the Second World War, and the massive investment made by the WHO and bi-lateral assistance. CQ was the main malaria therapy worldwide from the 1940s until the 1990s and Africa is highly vulnerable to the continuing availability of effective antimalarial drugs. That is why preserving drugs' effectiveness is essential. Following the emergence of CQ-resistant Plasmodium falciparum, most African countries discontinued the use of CQ, and now promote ACT as the first-line treatment. This change was generally initiated during the last decade in West and Central Africa (Gharbi et al. 2013). Indeed, in the late 90s, the Chinese drug artemisinin has been hailed as one of the greatest advances in fighting malaria, since the discovery of quinine centuries ago. Artemisinin was first extracted by the Chinese in 1971 from Artemisia Annua. This treatment was not new (Klayman 1985) but the first ACTs were provided at reduced prices to the WHO only in 2001. Approximately at the same time, in 1998, the WHO launched a second campaign aiming to halve malaria deaths worldwide by 2010 (Nabarro and Tayler 1998). The Global Fund (GF) to Fight AIDS, Tuberculosis and Malaria was created in 2002, and soon after its founding, became the main multi-lateral funder in the global health arena.

Nowadays, the primary objective of these new malaria control campaigns is to reduce deaths and illness from the disease. Elimination of infection is far more difficult. The policies and strategies for malaria control are based on LLINs and ACT, plus a revival of support for indoor residual 
spraying of insecticide (IRS). The combination of these actions has several advantages. First, ITNs are comparable to measles vaccination in their cost-effectiveness in preventing malaria deaths and morbidity and can be used for mosquitoes control and as a preventive measure. Second, the demise of CQ and sulfadoxine-pyrimethamine leaves ACT as the best treatment option. The advantages of ACTs (easy to administer, few side-effects, rapid action against the parasite, increase in the efficacy of both drugs) are widely recognized. In addition, patients given two or more effective drugs are less likely to encounter drug resistance and failed treatment, because parasite mutations to both components with different mechanisms of action are less probable. Currently there are six ACTs approved by regulatory authorities (Lin et al. 2010).4 Third, IRS is the application of insecticides to the inner surfaces of dwellings, where endophilic Anopheline mosquitoes often rest after taking a blood meal. According to WHO, several years of consecutive rounds of IRS are effective in reducing malaria parasite prevalence and incidence in areas of high transmission and can be used in combination with ITNs ${ }^{5}$. Last, Seasonal Malaria Chemoprevention (SMC) is recommended by the WHO in parts of the world where malaria is seasonal, such as the Sahel sub-region of Africa. Most childhood malaria mortality and morbidity occurs during the rainy season in these regions. The provision of effective malaria treatment at intervals during this period has been shown to prevent illness and death from malaria among children. 6

\subsection{The 'value for money' of malaria control programmes}

Growing value for money agenda aims to reduce costs, increase impact per US\$ spent, and focus investments on the highest impact interventions among the most affected populations (Fan et al. 2013; Glassman et al. 2013).

This agenda is all the more relevant as, according to the 2012 Malaria Report (WHO 2012), the past decade has witnessed tremendous expansion in the financing and implementation of malaria control programmes. International disbursements for malaria control rose steeply from less than US $\$ 100$ million in 2000 to US $\$ 1.71$ billion in 2010 , and were estimated to be US $\$ 1.66$ billion in 2011 and US $\$ 1.84$ billion in 2012. Analysis indicates that as funding has risen, international disbursements have been increasingly targeted to the African region (contrary to the first WHO campaign), to countries with the lowest gross national income (GNI) per capita, and to countries with the highest malaria mortality rates. Domestic government funding for malaria control programmes also increased through 2005-11, and was estimated at US\$625 million in 2011.

The paradigm shift from malaria control to malaria eradication following declarations at the Gates Malaria Forum in October 2007 and subsequent support voiced by WHO, the Board of the Roll Back Malaria (RBM) Partnership, the United Nations (UN) Secretary-General in 2011, and many other institutions has renewed inspiration for innovation and public health action. The GF remains the largest source of funding for malaria control globally, accounting for 39 per cent of estimated disbursed funds in 2011 and 40 per cent in 2012 (WHO 2012). The second and third largest funders are the President's Malaria Initiative and the World Bank's Booster programme. However, while there have been substantial increases in funding for malaria control, they continue to fall short of the amount needed to achieve the global goals. The Global Malaria

\footnotetext{
4 Artemether-lumefantrine; artesunate-amodiaquine; artesunate-mefloquine; artesunate-sulfadoxine-pyrimethamine; dihydroartemisinin-piperaquine; and artesunate-pyronaridine.

5 See Mabaso et al. (2004) for a historical review of malarial control in southern African with emphasis on the use of IRS.

${ }^{6}$ WHO recommends SMC with sulfadoxine-pyrimethamine and amodiaquine in areas with highly seasonal malaria transmission in the Sahel sub-region of SSA, where P. falciparum is sensitive to both antimalarial medicines.
} 
Action Plan (RBM 2013) estimates that US $\$ 2.196$ billion will be needed annually in 2015 to scale-up preventive and curative interventions to reach universal coverage in Africa.

In the past decade, a trend has appeared in malaria-induced mortality, with decreasing mortality around 2005 (Figure 1, and Murray et al. 2012). It is however difficult to assert a direct causal relationship of all malaria control policies because limited rigorous evaluations have been undertaken. It is possible that this favourable trend is mainly due to the spread of ACTs alone. ${ }^{7}$ However, attribution of this recent favourable trend to any of the policies that have been implemented is impossible due to the lack of measurement instruments and formal external large scale impact evaluations for interventions and service delivery strategies (Fan et al. 2013). Randomized studies are needed to assess the efficiency of such programmes and optimal combinations of actions from a supply side perspective.

Moreover, we have factual indications that a number of specific initiatives have had moderate positive or negative impact. First, subsidizing treatment may increase their usage among people who do not actually have malaria. Cohen et al. (2011) shows that only 25 percent of adults (over age 18) who purchased subsidized ACTs at drug shops were tested malaria positive. Second, as shown by Laxminarayan et al. (2010), at extremely high infection transmission rates (in excess of about 70 infectious bites per year), treatment subsidies may be inefficient because recovering individuals quickly become re-infected so that there is little impact on reducing the size of the infected population. Third, surveillance systems and research studies supported by WHO to monitor antimalarial drugs' efficacy in countries do provide evidence that parasites resistant to artemisinin have emerged along the border between Cambodia and Thailand.

In addition, proliferation of insecticide resistance suggests that the spread of insecticide resistance is a major threat for vector control programmes, especially pyrethroid resistance in Africa (Santolamazza et al. 2008). Currently, insecticides used for IRS come from only four classes: pyrethroids (the most commonly used class); organochlorines (of which DDT is the only compound in use); organophosphates; and carbamates; all WHO-recommended. ITNs and LLINs use pyrethroids. As malaria vector control, and consequently the success of global malaria control, is heavily reliant on a single class of insecticide, the pyrethroids, increasing resistance of malaria vectors to pyrethroids and to other insecticides jeopardizes global malaria control efforts.

Apart from technical considerations, the analysis of demand and supply chain of malaria control tools suggests a number of difficulties that may affect the effectiveness of policies that are currently implemented.

\subsection{Demand and supply chain}

Amongst potential explanations of a potential limited effect of malaria control, a number of different demand and supply side factors can influence malaria prevention and treatment. On the demand side, financial constraints are the main reasons given by households for not acquiring health products (Guyatt et al. 2002; Bates et al. 2004a, 2004b; Wiseman et al. 2007; Eisele et al. 2009; Afolabi et al. 2009; Krezanoski et al. 2010). Indeed, demand for these products appears quite price elastic. In Kenya, Cohen and Dupas (2008) found that pregnant women universally

\footnotetext{
7 Unfortunately, until now, the Global Price Reporting Mechanism (GPRM) hosted by the WHO website (a database recording international transactions of HIV, tuberculosis and malaria commodities purchased by national programmes in low- and middle-income countries) does not provide free access to the data on anti-malaria medicines.
} 
take up an antimalarial bed net when it is given for free during a prenatal visit, but only 40 per cent buy one at the still highly subsidized price of US\$0.60. Understanding this peculiar behaviour and its consequences for malaria control requires building an economicepidemiological model (see Section 4). In addition, bed net coverage remains inequitable among different socio-economic groups: higher income household are much more likely to possess a bed net (Matovu et al. 2009; Ye et al. 2012; García-Basteiro et al. 2011). However Onwujekwe et al. (2004) showed that demand for bed nets increases with income but less than proportionally. Lastly, Tarozzi et al. (2011) highlight the role of liquidity constraints in explaining low adoption rates.

On the supply side, health centres, dispensaries, and hospitals deliver different types of medical activities: curative and preventive healthcare services, in addition to daily health education, which are characterized by different production processes. The literature on the efficiency of healthcare systems in developing countries generally focuses on hospital level data or other aggregated data (health center, health district, regional or national levels). Patient level data or household data are generally less used for this specific purpose. Nevertheless, the choices people make vary considerably across Africa, depending on the type of delivery strategies that operate in that area. For instance, lack of availability and failure in ITN distribution systems have been identified by RBM as the main limitations (other than cost) of large-scale implementation of ITN use. Cumulative attrition across the different steps of distribution programmes, or small failures in the distribution process result in people dropping out of the system (Marchant et al. 2010). In a literature review of 127 reports and studies, Kilian et al. (2010) found that community-based distribution campaigns achieve rapid increases in bed net coverage, but this coverage fluctuates after a few years. Continuous distribution mechanisms (routine services, retail outlets, assisted or unassisted commercial markets) avoid these fluctuations but are much slower in building-up high coverage levels. ${ }^{8}$

Continuous promotion of effective maintenance and routine healthcare education is also needed and efforts to replace damaged nets must be implemented (Githinji et al. 2010). However, many of these strategies have not been assessed to date and only some of the existing cost-estimates have been derived using appropriate methods (Kolaczinski et al. 2010). Seban et al. (2013) use a household survey conducted in 2009 in Haut Katanga, Democratic Republic of Congo (DRC). They combine these data with estimates on malaria prevalence from the Malaria Atlas project. Results show that households behave rationally with respect to the disease. They also show that health centers are not the most effective in promoting possession of bed nets, in areas where they are most needed for malaria control. The governments of malaria-endemic countries often lack financial resources. As a consequence, health workers in the public sector are often underpaid and overworked. They lack equipment, drugs, training, and supervision. The local populations are aware of such situations when they occur, and cease relying on the public sector health facilities. Conversely, the private sector suffers from its own problems. Regulatory measures often do not exist or are not enforced. This encourages private consultations by unlicensed, costly health providers, and the anarchic prescription and sale of drugs (some of which are counterfeit products). Correcting this situation is a tremendous challenge that must be addressed if malaria control is to be successful.

\footnotetext{
8 Other reviews can be found in Stevens (2005); Hill et al. (2006); and Lengeler et al. (2007). Other studies analyse different delivery strategies and the cost-effectiveness of ITN/LLINs (Thomson et al. 1995; Goodman et al. 1999; Chima et al. 2003; Morel et al. 2005, Worrall et al., 2005, Chuma et al., 2006). For a literature survey of studies assessing the economic burden of malaria since 1909, see Packard (2009).
} 
If it is possible to analyse the causal effect of a programme, it is probably more difficult to analyse the causal effect of poor health on economic outcomes. This is also true for malaria. In economic terms, the total household cost burden of malaria is estimated to be high in Africa. Early estimates of total costs (Shepard et al. 1991) reported that the total cost of malaria for SSA was 0.6 per cent of total SSA GDP in 1987 and one per cent in 1995. At the household level, Worrall et al. (2005) provide an exhaustive literature survey and find mixed evidence on the effects of socio-economic status (probably due to endogeneity bias) on malaria incidence but find strong evidence that malaria prevention and treatment is related to socio-economic status.

\subsection{Malaria, poverty, and growth: a circular relationship?}

\section{The neoclassical approach}

In a neoclassical context, the impact of malaria on income per capita at the steady state will be theoretically undetermined: lower population growth rate leading to higher income per capita by reducing demographic pressure on savings (positive Malthusian effect), lower savings rate (because of a high healthcare expenditure and because the increase in the risk of dying reinforces the preference for the present) and therefore lower per capita product (negative effect), lower labour productivity (absenteeism, fatigue) entailing in a reduction in per capita output (negative effect).

Barlow (1967) examined the economic effects of malaria taking into account the multiplicity of these effects and integrating general equilibrium effects in a macroeconomic demographic model. He identified four effects of malaria eradication on per capita income: effects on population size (increase in population resulting from both declining mortality and rising fertility), effects on labour inputs (increase in labour supply and efficiency); effects on capital inputs (limited and unproductive private saving due to population growth and public investments); effects on output (exploitation of new territories). In his calibrated model, Barlow found a positive impact of malaria eradication in the short run and a negative impact in the long run in Ceylon between 1947 and 1965. Eradication led to immediate increase in labour quality and quantity (through reductions in morbidity and debility and decreased mortality). This increases income per equivalent consumer. After a while (1953-55), the negative effects of malaria eradication became prominent (increased population, decreased savings, higher demand on the public sector). In his model, the main economic disadvantage of a malaria-eradication programme is the rapid increase in the population of children. He suggested that these effects could be contained by birth control. However, Barlow's model is not without limits.

Following Newman's (1970) findings, Barlow (1967) supposes that malaria eradication will raise fertility, but the demographic effects of malaria are theoretically undetermined. Malaria can have three short-term effects on fertility (Lucas 2013): 1) a negative biological effect on fecundity; 2) economic theories predict that increased income and the decreased price of a surviving child will increase fertility (positive effect); 3) the demographic transition theories suggest that increased survival certainty and preferences for quality over quantity will decrease fertility (negative effect). There are two long-term demographic effects of malaria eradication on fertility: 1) women born after eradication will be healthier, leading to higher fertility; 2) if malaria has a negative effect on education, their additional education increases their opportunity cost of time, potentially lowering total fertility. For instance, Lucas (2013) finds that the initial effect of malaria 
eradication in Sri-Lanka (1937-53) was actually an increase in fertility (because of the biological effect) but the next generation had lower fertility and higher education. Therefore, while the initial population growth might be detrimental to gross domestic product GDP per capita, increased education and lower subsequent fertility can mitigate this initial negative growth effect. This seems contradictory to Barlow's findings. It is possible that Barlow's long run was insufficiently long. Another controversial aspect of Barlow's (1967) hypotheses is that he considers that the malaria eradication will 'impose burdens on the educational sector' due to the massive enrolment of new cohorts of children as time progresses. Investments in health are not supposed to improve the quality of the workforce through children's human capital accumulation in his model, while the influence of malaria on cognitive capacity of the children is now relatively well documented (see below).

\subsection{Empirical studies on the macroeconomic effects of Malaria}

A series of papers have explored the link between economic development and malaria. ${ }^{9}$ Contrary to other tropical diseases and since the failure of eradication efforts in the 1980s, malaria has been described as an unavoidable effect of tropical location and natural forces (i.e., heavy rains, floods).

Gallup and Sachs (2000), using a malaria exposure index defined as the fraction of population at risk of contracting falciparum malaria in a country, show that poverty is not a leading cause of malaria, ceteris paribus. In a cross-country regression framework, the authors find that countries with intensive malaria are poorer and have grown 1.3 per cent less per person per year. These results point to malaria's causing poverty, not vice versa.

In another article, McCarthy et al. (2000), using estimates of malaria morbidity from the WHO, suggest that economic development may influence malaria control. They confirm the dominant role of climate in determining malaria intensity and the negative correlation between malaria and growth but they find that access to rural healthcare and income equality also influence malaria morbidity once one controls for climate. This finding raises the problem of the endogeneity of malaria with respect to growth and the robustness of the results in this field of research.

In contrast, in Acemoglu et al. (2003a), malaria 'is unlikely to be the reason why many countries in Africa and Asia are very poor today'. More generally, Acemoglu and Johnson (2007) also cast doubt on the causal relationship between bad health conditions and poverty.

It is now clear that Gallup and Sachs (2001) or McCarthy et al. (2000) studies did not prove that malaria is a cause of low incomes and poor economic growth. Many other changes occurred simultaneously in the economies where malaria has been eliminated. Malaria eradication can be correlated with many other factors that influence economic growth including governance and the quality of public policies that have been omitted from econometric models. Packard (2009) notes that 'given the multiple difficulties associated with past efforts to demonstrate the impact of malaria on economic development and the economic benefits of malaria control, it is surprising that Gallup and Sachs stated their conclusions with such confidence and that their conclusions have been accepted with so little question.'

\footnotetext{
9 See for instance McDonald (1950); Barlow (1967); Newman (1968); Gomes (1993); Audibert et al. (1999); and Bowden et al. (2008).
} 
However, the terrible toll on the health and well-being of people living in malaria-endemic or epidemic areas and the convergence between different studies 10 prove at least that the disease could be considered a potential legitimate contributor of poor economic performance (Arrow 2004). The macroeconomic literature is relatively poor compared to the microeconomic literature on malaria. Although macroeconomic effects are not the mere aggregate of microeconomic results, it seems legitimate that, in the absence of reliable aggregate data on malaria and of relevant macroeconomic instruments, that would help to solve the endogeneity issue, most of the recent research on this topic takes a microeconomic orientation.

\subsection{Cost analysis of malaria in Africa: direct, indirect, and opportunity costs}

\section{The buman capital approach}

To disentangle the relationship between malaria and poverty we need to establish an accurate account of the costs of malaria. Microeconomic studies on malaria mostly use the human capital approach. This approach leads one to estimate the costs of malaria on various levels: those incurred by individuals and households, public health services and governments, and other private agents (firms, non-governmental institutions for instance). Direct or immediate costs are distinguished from indirect costs.

Direct costs on household and individual level are expenditures related to prevention and treatment. Seeking treatments at health centers, buying drugs, and arranging funerals entail obvious financial costs. For the private business sector, the cost of private healthcare provided by employers may rise. For public health services, public expenditures for malaria prevention and treatment may be substantial even if they are not easily quantified. This lack of quantification can result in a reduction in the standard of care for all patients.

Indirect costs include, among others, lost time due to illness (such as time spent seeking care), long-term losses in household productivity and income, absenteeism from work or school, decline in activity in various sectors, and excessive use of government resources on related expenditures. Studies on the indirect cost vary widely in their methods and in what they try to assess.

Opportunity costs are the costs of spending time and effort to avoid the disease rather than using these resources for an economically productive activity, or the cost equal to what an individual must give up in order to avoid or cure malaria.

\section{Specific channels through education and productivity}

One area where malaria may have a detrimental effect on economic growth is its impact on the health and mental development of children. For instance, Thuilliez (2010a, 2010b) shows that the relationship between school results (measured by class repeat and completion rates) and $P$. falciparum malaria is strong at the macroeconomic and community levels. There are a number of ways through which malaria can impact children's educational achievement, even if the precise medical mechanisms for the effects of malaria on education and learning remain unknown. ${ }^{11}$

\footnotetext{
10 See for instance Shepard et al. (1991) and Chima et al. (2003).

${ }^{11}$ Thuilliez et al. (2010) provides a detailed discussion on potential mechanisms involved in this relationship.
} 
First, because of depressed acquired immunity during pregnancy, malaria is a real threat for both pregnant women and the foetus. Indeed, malaria can lead to anaemia, increased risk of premature delivery, low birth weight and foetal growth retardation, which may translate into cognitive, physical or development impairments. Barreca (2010) analyses the long-term economic impact of in utero and postnatal exposure to malaria and finds substantial effects on educational attainment in adulthood.

Second, among children under the age of five, complicated forms of malaria may develop rapidly. The effects of severe malaria, better known as cerebral malaria (CM), have been quantified by numerous studies. 12 For instance, Ngoungou et al. (2007) provide a quantification of the burden in Mali. 101 subjects (mean age was 5.6 \pm 3.6 years) who had had CM in Mali were followed from 1999 to 2001. The authors find that 28 children presented persistent neurological sequelae (26.7 per cent). Among them, eight ( 7.9 per cent) children had developed these sequelae just after CM and 20 (19.8 per cent) a few months later. These included headaches, mental retardation, speech delay, bucco-facial dyspraxia, diplegia and frontal syndrome (one case each), dystonia (two cases), epilepsy (five cases), and behaviour and attention disorders (15 cases). This study shows that neurological signs due to CM can persist in the long run (or at least a few months after). Many other studies have analysed the relationship between severe falciparum malaria and developmental and long-term cognitive impairment (Carter et al. 2005; Boivin et al. 2007; John et al. 2008).

Third, even during late childhood (which usually extends from six to 16 years of age), the protection conferred by acquired immunity is only partial. If CM is rare at this stage, uncomplicated malaria, repeated illness, or chronic malaria infections are not. They can have a non-cognitive impact on educational achievement through school absenteeism, general health conditions, and investment in curative strategies (coping strategies against the disease detrimental to educational investments). For instance in a Kenyan case study, Brooker et al. (2000) attribute 13-50 per cent of medically related school absences to malaria. In Kenya, primary school students were determined to miss 11 per cent of the school year (20 school days missed per child/year). In Nigeria, school days missed varied between two per cent to six per cent of the school year (three to 12 days per year per student). In Mali, malaria was the primary cause of absenteeism during a full school year (Thuilliez et al. 2010). Moreover, although the age distribution of uncomplicated malaria and asymptomatic malaria depends on transmission intensity, the total burden of disease may be similar or even higher in settings of low transmission due to patterns of acquired immunity. Malaria morbidity among school-age children increases as transmission intensity decreases, but asymptomatic infections are more frequent in high-transmission settings (Clarke et al. 2004; Dicko et al. 2007). Fernando et al. (2003) show a significant negative correlation between the total number of malarial attacks experienced by children and test scores during a six year follow-up. Fernando et al. (2006) and Jukes et al. (2009) also show a substantial effect of preventive treatment in two randomized studies. Yet, asymptomatic malaria has proven to have detrimental effects on children's cognitive and educational skills in three studies, one being a cluster-randomized control trial which suggests either a direct causal effect of the disease or an antimalarial treatment effect (Clarke et al. 2008; Thuilliez et al. 2010; Nankabirwa et al. 2013), although confirmatory studies are needed. The mechanism could include a 'toxicity effect, leading to biochemical changes in the central nervous system (CNS); excitation of the immune system, leading to changes in behaviours related to appetite and reaction time; and physiological effects such as discomfort and disturbed sleep, leading to reductions in activity levels or causing behavioural change' (Holding and Snow 2001).

12 A literature review (1960-2002) can be found in Mung'Ala-Odera et al. (2004). 
Another area where malaria may have a detrimental effect on economic growth is its impact on productivity. The effect of malaria on farmers' productivity and efficiency has been the subject of careful research (Conly 1975; Audibert et al. 1990, 1999, 2003, 2009; Leighton and Foster 1993). The results from Audibert et al. (2009) suggest that the effect depends on the type of agricultural activity. Indeed malaria has no effect on coffee and cocoa productions but reduces technical efficiency in the cultivation of cotton. One difficulty tackled in later articles on efficiency relates to coping or anticipatory coping strategies adopted by the families (particularly wealthy families) that bias the estimated effects of the disease on production and productivity. The size and direction of this bias depends on the conditions of the labour market and on epidemiologic conditions. Other difficulties come from measurement errors related to health variables, omitted variables or reverse causality leading to endogeneity problems (Strauss 1986). This difficulty suggests the necessity to measure malaria on a very thin scale as the morbidity effects on productivity are often measured imperfectly. Notably asymptomatic malaria in intense transmission area probably has little effects on agricultural productivity as individuals are not strongly invalidated physically.

\section{Natural experiments}

Natural experiments do not analyse the direct effect of the disease but provide estimates of the effects of interventions in real world context, in complement to randomized trials used for evaluation in experimental context (already mentioned in Section 2). In a recent paper with a historical perspective, Bleakley (2010) considers the malaria-eradication campaigns in the United States (1920), Brazil, Colombia and Mexico (1950) to assess the impact of childhood exposure to malaria on labour productivity. Using a cohort-level dataset based on microeconomic data, Bleakley finds that cohorts born after eradication enjoyed higher levels of income and literacy as adult than the preceding generation. In India, Cutler et al. (2010), using a similar quasiexperimental framework, find modest increases in income levels for men but not for women and no evidence of increased educational attainment for men but mixed evidence for women. Lastly, one limitation of these studies is that they use data from the 'malaria periphery', defined by Lucas (2010) as areas in which malaria transmission was primarily seasonal or epidemic before eradication. These countries have particular epidemiological settings and were classified as $P$. vivax-dominant areas before eradication campaigns. Thus, they are generally unaffected by the most severe P.falciparum malaria, and the external validity is limited to these areas. In Africa, Kuecken et al. (2013) examine the medium-term effects of the GF's malaria control programmes on the educational attainment of primary schoolchildren in SSA using a quasi-experimental approach. In the majority of countries (14 of 22), they find that the programme led to substantial increases in years of schooling and grade level as well as reductions in schooling delay.

Mosquito vectors have often been seen as promise to solve malaria endogeneity problem in economic studies. For instance, this line of arguments has first been used for cross-country analysis by Sachs (2003) or recently by Bleakley (2010). The latter uses a malaria ecology index as an instrumental variable for malaria prevalence at a county level. Biological properties of regionally dominant malaria vectors (longevity and human-biting habit) and thus the force of infection, is said to be exogenous to public interventions and economic conditions (Kiszewski et al. 2004). Even if many authors doubted the exogeneity of malaria ecology at the macroeconomic level (Rodrik et al. 2004; Acemoglu et al. 2003a, 2003b), Bhattacharyya (2009) as well as Carstensen and Gundlach (2006) claimed that these doubts may not be justified because the region-specific dominant malaria vector reflects only the forces of biological evolution. 


\section{$4 \quad$ Malaria economic epidemiology}

\subsection{Fees and behavioural factors}

Bates et al. (2012) provides a literature review of randomized experiments on price-elasticity of health products, including malaria specific measures. The results show that charging small fees in an attempt to balance access and 'sustainability' may not be a good solution, as relative to free distribution, charging even very small user fees substantially reduces adoption, i.e., charging does not encourage use. Behavioural obstacles to efficient control and/or eradication of malaria also appear to have been underestimated. ITNs have reduced malaria transmission and child morbidity in short-term trials. However, as shown by various papers (Rhee et al. 2005; Toé et al. 2009), even in experimental contexts in small communities where education on malaria and use of nets was given before net distribution, the proportion of households that used the nets remained low. Use also tended to decrease a few months after the programme. Studies in Burkina Faso (Toé et al. 2009) and Madagascar (Krezanoski et al. 2010) revealed that there was a high rate of ITN use for the first few months but that the rate of use subsequently fell for apparently non-objective reasons. This could be due to motivation (Toé et al. 2009), seasonal factors because people stopped using nets when mosquitoes were less noticeable (Baume and Marin 2007), individual perception and room organization (Toé et al. 2009). Toé et al. also stressed that there had been very few evaluations of the short- and long-term impact of motivation campaigns. Their study showed that 'LLINs were not used when the perceived benefits of reduction in mosquito nuisance and of malaria were considered not to be worth the inconvenience of daily use.' Marchant et al. (2010) also suggested that there might be additional barriers to using an insecticide-treated net, especially among the poor. 'Providing incentives for behaviour change is a promising tool that can complement traditional ITN distribution programmes and improve the effectiveness of ITN programmes in protecting vulnerable populations' (Krezanoski et al. 2010).

Berthélemy et al. (2010) provide a theoretical argument to explain such results by economically rational behaviours. When integrated into a dynamical framework this analysis allows for an explanation of the probable endogenous relationship between malaria and poverty, leading to a malaria-related poverty trap, and an integration of possible externalities.

\subsection{Is there a malaria-related poverty trap?}

This section proposes a model for malaria economic analysis by combining economic epidemiology tools with the literature on poverty traps (the full model being provided in Berthélemy et al. 2013). A theoretical model of rational protective behaviour in response to malaria is designed, which includes endogenous externalities and disease characteristics.

A standard epidemiological model of malaria was built, with transmission of malaria between a population of humans and a population of mosquitoes (Smith and McKenzie 2004). Simplifying assumptions have been assumed: constant population sizes (human and mosquito) over time, uniform contacts between human and mosquitoes, ignorance of superinfection and immunity. Within the life-time period of humans, malaria prevalence among humans and mosquitoes reaches a steady state. This leads, in absence of protection, to equations based on the McDonald and Ross malaria transmission model (Smith and McKenzie 2004).

The time variation of malaria prevalence among humans can be defined in a simplified way as: 
where $m$ is the vector density (ratio of mosquitoes per human), $a$ is the number of bits per unit of time and per mosquito, $b$ is the proportion of infected bites that produce infection among humans, $Z$ is the proportion of infectious mosquitoes, and $r$ is the clearance rate of malaria in humans.

Similarly, the variation of the proportion of infectious mosquitoes can be written as:

$\dot{Z}=a c X\left(e^{-g n}-Z\right)-g Z$

where $c$ is the proportion of bites on infectious humans that produce infection among mosquitoes, $g$ is the death rate of mosquitoes, and $n$ is the length of sporogonic cycle.

Assuming that the time period of life is long enough, malaria prevalence reaches a steady state equilibrium defined by a function $Q(X, \mathrm{~m})$, which depends on all parameters defined in Equations (1) and (2) (see Berthélemy et al. 2013).

This function is concave, and characterized by the following properties:

$\left\{\begin{array}{l}Q(0, m)=0 \\ Q(1, m)<1\end{array}\right.$

And its slope at origin is equal to a number, $R_{0}$, that is classically called in the MacDonald (1950, $1957)$ and Ross tradition the 'basic reproduction rate'. If $R_{0}$ is below or equal to 1 , then $Q(X, m)$ converges towards the trivial disease free stable steady state. This case is not considered in what follows, as it does not coincide with the persistence of malaria in large regions of the developing world. Conversely, if $R_{0}$ is higher than 1 , then $Q(X, m)$ converges towards a stable steady state characterized by a strictly positive prevalence of malaria.

\subsection{Economic epidemiological model with protection}

When the basic reproduction number $R_{0}$ is higher than 1 , using protection tools could nevertheless reduce malaria transmission, and then, the trivial disease free stable steady state could be reached. This is the rationale of ITN/LLINs dissemination policies. In order to assess this possibility, a model of protection behaviour has been added to the previous epidemiological model. This behavioural model, as described below, is based on economic mechanisms. Peoples adopt certain behaviours: use of an insecticide-treated net $(h=1)$ or exposure to malaria risk $(h=0)$. It is supposed that the only means by which a person can prevent himself from parasitic infection is to sleep under an ITN/LLIN (even if a person can be infected during the first part of the night). As a first assumption, the use of an ITN/LLIN was supposed to provide complete protection from malaria infection. This assumption can be relaxed without affecting the main findings of the model (Berthélemy et al. 2013). At any time, depending on the use of ITN before, the health status of the individual, $\sigma(h)$ can take one of two values: susceptible, $\sigma(h)=S$, or infected, $\sigma(h)=I$. The probability of being infected at any time, conditionally to the absence of protection before, can then be written as:

$\pi_{I}=P(\sigma(h)=I / h=0)$ 
and this probability $\pi_{\mathrm{I}}$ is equal to the value of the $\mathrm{Q}(\mathrm{X}, \mathrm{m})$ function defined in the epidemiological model in absence of protection.

If $H$ is the proportion of population using ITN/LLIN, among the (1-X) uninfected persons, the proportion of infected persons can be simply written as:

$X=(1-H) \pi_{I}$

Furthermore the density of mosquitoes in contact to humans, $m$, is affected by the presence of ITN/LLIN used by a proportion $H$ of the population. First, as the contact between mosquito and human is more difficult, the denominator of the mosquito density decreases, being now the proportion 1- $H$ of non-protected population. Second, as ITN/LLINs do not only protect humans, from anopheles bites, but also kill mosquitoes (knock down effect), the numerator (the number of mosquitoes) decreases with $H$. Hence $m$, which was a parameter in the pure epidemiological model, can be now written as a function of $\mathrm{H}$ as follows:

$m(H)=\frac{m[0]}{1-H}(1-\gamma(H))$

Where $\gamma(H)$ is the proportion of mosquitoes killed by the use of ITN/LLINs, an increasing function of $H$.

It follows that, at the steady state:

$\pi_{I}=Q(X, m(H))$

In order to complete the model, the determinants of $\mathrm{H}$ were specified in a next step. At the microeconomic level, the choice of protection is determined by maximizing the expected utility of each individual. The decision $h$ of protection ( $h=1$ for protection, $h=0$ for non-protection) affects individuals' utility through two channels: (i) an expected positive impact on their health status in case of protection and (ii) a private cost, called $x$. Hence protection decision is described through the following maximization programme:

$\max _{h} E[u(\sigma(h))]-\kappa W(\omega) h$

Where $u(S)$ or $u(I)$ are the utility levels attached to the health status (susceptible, $\sigma(h)=S$, or infected, $\sigma(h)=I$, thus depending on $h$, the use of a protection), with $0<u(I)<u(S)$; $\omega$ is

the individual income; $W(\omega)$ is the marginal utility of the income $\omega$, supposed as usual to decrease with income.

The expected utility (the expected positive impact of using ITN/LLIN on the health status) can be estimated using the following probabilities of being susceptible or infected, conditionally to the use of protection:

$$
\begin{aligned}
& P(\sigma(h)=S / h=1)=1 \\
& P(\sigma(h)=S / h=0)=1-\pi_{I} \\
& P(\sigma(h)=I / h=0)=\pi_{I}
\end{aligned}
$$


In addition, it is assumed that there exists a minimum subsistence level, such as in the case a Stone-Geary utility function. This implies that the marginal utility of income $W(\omega)$ goes to infinity for all individuals at (or below) the minimum subsistence level, which is classically called the extreme poverty line $\Omega$ (i.e. the minimum level of income deemed adequate in a given country for an individual or a household). In other words, the extreme poverty line is an income level below which nobody can afford an ITN/LLIN, i.e. $h=0$.

As in standard economic epidemiological models, the individual will use protective tools when $W(\omega)$ is lower than the expected utility loss associated with the risk of infection that occurs in the absence of protection:

$E[u(\sigma(1))-u(\sigma(0))] \geq \kappa W(\omega)$

According to Equation 9 and the three probabilities of Equation 10 it follows that:

$h=1$ if and only if $u(S)-\left(1-\pi_{I}\right) u(S)-\pi_{I} u(I) \geq \kappa W(\omega)$

A person will use ITN/LLIN if the utility of being non-infected is greater than the utility of paying for a protective tool, according to the income and the probability of being infected without using any protection. Hence, protection occurs if and only if:

$\pi_{I} \geq \frac{\kappa W(\omega)}{u(s)-u(I)}$

This equation shows that there is a threshold probability of infection above which a person engages in protection. The key point in this approach is that the threshold probability of infection depends on the marginal income utility loss associated with using the ITN/LLIN, $\kappa W(\omega)$, with respect to the net value attached to susceptible health status, $u(S)-u(I)$. This threshold depends on the individual income $\omega$. The threshold function, linking $\pi_{I}$ to $\omega$, termed $C(\omega)$, is monotonic and $C^{\prime}(\omega)<0$, as the function $W 0$ is monotonic and $W^{\prime}(\omega)<0$. In addition, the function $C O$ is increasing with $\kappa$. Consequently:

$\left\{\begin{array}{l}h=1 \text { if } \omega \geq C^{-1}\left(\pi_{I}\right) \\ h=0 \text { else }\end{array}\right.$

and the income threshold conditioning protection, $C^{-1}\left(\pi_{I}\right)$, decreases with $\kappa$. Knowing individual protection behaviours, the aggregated level of protection $H$ (the percentage of protected persons) can be computed by integration as follows:

$H=\int_{C^{-1}\left(\pi_{R}\right)}^{+\infty} f(\omega) d \omega=1-F\left(C^{-1}\left(\pi_{I}\right)\right)$

Where $f$ is the probability density function of $\omega$ (and $F$ the associated cumulative density function), describing the income distribution of the population. Equations 6, 8, and 13 fully describes the dynamics of $H$ and $\pi_{I}$ as a function of $X$. 


\subsection{Prevalence-elastic behaviour at the steady-state vicinity}

Nearby the steady-state, the dynamics corresponds to a standard prevalence-elastic behaviour of protection (positive malaria prevalence elasticity), where $H$ is an increasing function of $X$, because it is increasing with $\pi_{I}$ (Equations 8 and 13). Note that as a consequence, nearby the steady-state, $X$ is not necessarily monotonic in $\pi_{i}$ : protection behaviours and epidemiological dynamics go in opposite directions. This is consistent with standard results in economic epidemiology.

More precisely, combining Equations (6) and (15) it follows that:

$X=F\left(C^{-1}\left(\pi_{l}\right)\right) \pi_{I}$

This equation provides us with some economic determinants of protection at individual and aggregated levels, that could be possibly tested (see Berthelemy et al. 2013, for tests on Ugandan data). For a given probability of infection in absence of protection, protection decreases with the unit costs of ITN/LLIN, $\kappa$ (through the function $C^{-1}$ ). It also decreases with poverty, as the poorer the individuals, the higher their marginal utility of income.

\subsection{Long-term properties: conditions of persistence of a malaria trap}

The main question to be solved, concerning the long-term properties of this model at the steadystate, is whether malaria can persist in the long run, in spite of the availability of ITN/LLINs as protection tools since the higher the unit cost $x$ of ITN/LLINs, the lower the protection. This is why ITN/LLINs programmes are usually based on subsidized ITN/LLINs prices. Let us then consider the best case of almost full subsidization, when $x \rightarrow 0$ (i.e. the extreme case being free distribution). Conditions under which, for any positive unit cost $x$, the malaria trap persists are given below.

\section{Proposition}

For any $x>0$, when $x \rightarrow 0$ the long term equilibrium corresponds to a persistence of malaria, if and

only if $R_{0}>\frac{1}{F(0)(1-m(R(N)))}$

where $F(\Omega)$ is the proportion of persons under the extreme poverty line in a population, also called the extreme poverty incidence. Note that $m$ depends on $H$, the proportion of protected persons (Equation 7), which depends itself on income (Equation 13), and, thus, on the extreme poverty incidence.

Given $\kappa \rightarrow 0$ and $H \rightarrow 1-F(\Omega)$, as the vector density $m$ is a decreasing function of $H$, the higher the incidence of extreme poverty $F(\Omega)$, the higher the risk of persistence of malaria. Hence, malaria will persist for high enough values of the basic reproduction number $R_{0}$ and of the extreme poverty incidence $F(\Omega)$, even when ITN/LLINs are highly subsidized. In the 
extreme case where all the population is at or below the extreme poverty line, the condition above corresponds exactly to the basic reproduction number, and hence this policy is certainly ineffective as long as $R_{0}>1$.

One could argue that if ITN/LLINs were provided at no cost to individuals $(\kappa=0)$, then all individuals including the extreme poor, would use them. Distribution of ITN/LLINs for free would then possibly be a much more efficient policy to reduce malaria, compared to selling ITN/LLINs at a subsidized price. This is in line with randomized experiments that found that free distribution dramatically increases use of ITN/LLINs (as well as other important products for the poor), compared to charging even very small user fees (Bates et al. 2012).

Nevertheless, the assumption $\kappa=0$ is merely theoretical, even though it can be possibly obtained in controlled experiments, as in practice $\kappa$ is not only the price of ITN/LLINs: It involves also all opportunity costs attached to using them for other productive activities. Selling, exchanging, discarding, or re-using the material from ITN/LLINs is not uncommon. For instance, misuse of ITN/LLINs for profit (drying fish and fishing) has been observed by Lake Victoria (Minakawa et al. 2008) and in Zambia (Hopkin 2008). In some cases, nets have even been turned into wedding dresses and water filters.

Two important conclusions emerge from the model. First, agents increase their protective behaviour when malaria is more prevalent in a society. This is consistent with the literature on 'prevalence-elastic behaviour'. Second, a malaria-related poverty trap defined as the result of malaria reinforcing poverty while poverty reduces the ability to deal with malaria can theoretically exist and the conditions of existence of this trap are identified. Typically it can be observed when the incidence of extreme poverty is initially very high.

Survey data available for Uganda provide empirical support to the theory of prevalence-elastic protection behaviours, once endogeneity issues related to epidemiology and poverty are solved (Berthélemy et al. 2013), and to the possibility of a malaria-related poverty trap.

\section{Conclusions}

Malaria is a major disease in SSA, which imposes a heavy human and economic toll on this region. Some of the first analyses on the cost of malaria, which attributed a very large economic cost to this disease, went probably too far in attributing a significant part of the African economic difficulties to malaria. Careful considerations on the bi-directional causality between malaria and poverty or aggregate underdevelopment suggest that the cost of malaria have been initially overestimated.

Nevertheless, such cost cannot be neglected, and policies to control malaria have received more and more attention in the past decade from the development aid community, notably through initiatives funded by the GF.

These policies, combining subsidization of new ACT treatments and the dissemination of protection/eradication tools, such as ITN/LLINs and IRS, have been coincidental with a recent trend of reduction of malaria mortality in Africa. These policies are, however, not without difficulties and attributing the small successes observed recently to such policies, or identifying the right mix of policy instruments, are extremely difficult. 
As for ACTs, the risk of fast-developing drug-resistance cannot be averted. From a policy point of view, Laxminarayan et al. (2010) have shown in this context the limits of policy of subsidization of ACTs .

As for ITN/LLINs and IRS dissemination, there are also risks of development of resistance to insecticides. Nevertheless, ITN/LLINs are still considered as technically efficient protection tools. In spite of this, the dissemination of ITN/LLINs is very far from satisfactory across the African continent. Beyond possible shortcomings in the supply chain, we point here to another possible difficulty, on the demand side. We have developed an epidemiologic-economic model in which the demand for ITN/LLINs is prevalent-elastic, which in turn leads to situations where the objective of malaria eradication may be out of reach. In particular, we show that in a context of a large extreme poverty incidence, the demand for ITN/LLINS may be too low to allow for complete malaria eradication.

Given these difficulties, the optimal strategy is probably a combination of the different tools. However, more analytical work, combining epidemiological and economic models, and more large-scale impact evaluations of the policies that have been implemented, are needed to make progresses in the identification of the right strategy. Given the heavy toll of malaria in Africa, this agenda of research should be given a high priority by economists and epidemiologists.

\section{References}

Acemoglu, D. and S. Johnson (2007). Disease and Development: The Effect of Life Expectancy on Economic Growth'. Journal of Political Economy, 115: 925-85.

Acemoglu, D., S. Johnson, and J. Robinson (2003a). 'Disease and Development in Historical Perspective'. Journal of the European Economic Association, 1: 397-405.

Acemoglu, D., S. Johnson, J. Robinson, and Y. Thaicharoen (2003b). 'Institutional Causes, Macroeconomic Symptoms: Volatility, Crises and Growth'. Journal of Monetary Economics, 50: 49-123.

Afolabi, B.M., O.T. Sofola, B.S. Fatunmbi, W. Komakech, F. Okoh, O. Saliu, P. Otsemobor, O.B. Oresanya, C.N. Amajoh, D. Fasiku, and I. Jalingo (2009). 'Household Possession, Use and Non-use of Treated or Untreated Mosquito Nets in Two Ecologically Diverse Regions of Nigeria-Niger Delta and Sahel Savannah'. Malaria Journal, 8: 30.

Alilio, M.S., I.C. Bygbjerg, and J.G. Breman (2004). 'Are Multilateral Malaria Research and Control Programs the Most Successful? Lessons from the Past 100 Years in Africa'. American Journal of Tropical Medicine and Hygiene, 71(Suppl 2): 268-78. http://www.ncbi.nlm.nih.gov/books/NBK3776/

Arrow, K.J., C. Panosian, and H. Gelband (2004). Saving lives, buying time: economics of malaria drugs in an age of resistance. Washington, DC: National Academies Press. http://books.google.fr/books?hl=frandlr=andid=PL8EmnGt71sCandoi=fndandpg $=$ PA1a nddq=Arrow, $+2004+$ saving + time+livesandots=8JwaLapLXwandsig=Kv7GKjZ4jHgjuH7 $\underline{B a-M Z F 857 E 00}$

Audibert, M., R. Josseran, R. Josse, and A. Adjidji (1990). 'Irrigation, Schistosomiasis, and Malaria in the Logone Valley, Cameroon'. American Journal of Tropical Medicine and Hygiene. 42: 550-60. 
Audibert, M., J. Mathonnat, and M.-C. Henry (2003). 'Malaria and Property Accumulation in Rice Production Systems in the Savannah Zone of Côte d'Ivoire'. Tropical Medicine and International Health, 8: 471-83.

Audibert, M., J.-F. Brun, and J. Mathonnat (2009). 'Effets économiques du paludisme sur les cultures de rente: l'exemple du café et du cacao en Côte d'Ivoire'. Revue d'économie du développement, 23: 145-66.

Audibert, M., J. Mathonnat, I. Nzeyimana, and M.-C. Henry (1999). 'Rôle du paludisme dans l'efficience technique des producteurs de coton dans le nord de la Côte d'Ivoire'. Revue d'Economie du Développement, volume spécial Santé et Développement, 4: 121-48.

Audibert, M., J. Mathonnat, and M.-C. Henry (2003). 'Social and Health Determinants of the Efficiency of Cotton Farmers in Northern Côte d'Ivoire'. Social Science and Medicine, 56: 1705-17.

Barlow, R. (1967). 'The Economic Effects of Malaria Eradication'. The American Economic Review, 57: 130-48.

Barreca, A.I. (2010). 'The Long-term Economic Impact of in Utero and Postnatal Exposure to Malaria'. Journal of Human Resources, 45: 865-92.

Bates, I., C. Fenton, J. Gruber, D. Lalloo, A. Medina Lara, S.B. Squire, S. Theobald, R. Thomson, and R. Tolhurst (2004). 'Vulnerability to Malaria, Tuberculosis, and HIV/AIDS Infection and Disease. Part 1: Determinants Operating at Individual and Household Level'. The Lancet Infectious Diseases, 4: 267-77.

Bates, M.A., R. Glennerster, K. Gumede, and E. Duflo (2012). 'The Price is Wrong'. Field Actions Science Reports. Special Issue 4: Fighting Poverty, Between Market and Gift. http:// factsreports.revues.org/1554

Baume, C.A. and M.C. Marin (2007). 'Intra-household Mosquito Net Use in Ethiopia, Ghana, Mali, Nigeria, Senegal, and Zambia: Are Nets Being Used? Who in the Household Uses 'Them?'. American Journal of Tropical Medicine and Hygiene, 77: 963-71.

Berthélemy, J.-C., J. Thuilliez, O. Doumbo, and J. Gaudart (2013). 'Malaria and Protective Behaviours: Is There a Malaria Trap?'. Malaria Journal, 12: 200.

Bhattacharyya, S. (2009). 'Root Causes of African Underdevelopment'. Journal of African Economies, 18: 745-80.

Bleakley, H. (2003). 'Disease and Development: Evidence from the American South'. Journal of the European Economic Association, 1: 376-86.

Boivin, M.J., P. Bangirana, J. Byarugaba, R.O. Opoka, R. Idro, A.M. Jurek, and C.C. John (2007). 'Cognitive Impairment After Cerebral Malaria in Children: A Prospective Study'. Pediatrics, 119: e360-66.

Bowden, S., D.M. Michailidou, and A. Pereira (2008). 'Chasing Mosquitoes: An Exploration of the Relationship Between Economic Growth, Poverty and the Elimination of Malaria in Southern Europe in the 20th century'. Journal of International Development, 20: 1080-06.

Hopkin, M. (2008). 'Malaria: The Big Push'. Nature, 451: 1047-49.

Brooker S., H. Guyatt, J. Omumbo, R. Shretta, L. Drake, and J. Ouma (2000). 'Situation Analysis of Malaria in School-aged Children in Kenya-What Can Be Done?'. Parasitology Today, 16: 183-86.

Carstensen, K. and E. Gundlach (2006). 'The Primacy of Institutions Reconsidered: Direct Income Effects of Malaria Prevalence'. World Bank Economic Review, 20: 309-39. 
Carter, R. and K.N. Mendis (2002). 'Evolutionary and Historical Aspects of the Burden of Malaria'. Clinical Microbiology Review, 15: 564-94.

Chima, R.I., C.A. Goodman, and A. Mills (2003). 'The Economic Impact of Malaria in Africa: A Critical Review of the Evidence'. Health policy, 63: 17-36.

Chuma, J.M., M. Thiede, and C.S. Molyneux (2006). 'Rethinking the Economic Costs of Malaria at the Household Level: Evidence from Applying a New Analytical Framework in Rural Kenya'. Malaria Journal, 5: 76.

Clarke, S.E., S. Brooker, J.K. Njagi, E. Njau, B. Estambale Benson; E. Muchiri, and P. Magnussen (2004). 'Malaria Morbidity Among School Children Living in Two Areas of Contrasting Transmission in Western Kenya. American Journal of Tropical Medicine and Hygiene, 71(6): 732-38. http://erepository.uonbi.ac.ke/handle/123456789/31858

Clarke, S.E., M.C. Jukes, J.K. Njagi, L. Khasakhala, B. Cundill, J. Otido, C. Crudder, B.B. Estambale, and S. Brooker (2008). 'Effect of Intermittent Preventive Treatment of Malaria on Health and Education in Schoolchildren: A Cluster-randomised, Double-blind, Placebocontrolled Trial'. The Lancet, 372: 127-38.

Cohen, J. and P. Dupas (2008). Free distribution or cost-sharing? evidence from a malaria prevention experiment. Cambridge, MA: NBER. http://www.nber.org/papers/w14406

Cohen, Jessica, Pascaline Dupas, and Simone Schaner. 2011. "Price Subsidies, Diagnostic Tests, and Targeting of Malaria Treatment: Evidence from a Randomized Controlled Trial." Working Paper: Abdul Latif Jameel Poverty Action Lab. Available at povertyactionlab.org.

Conly, G.N. (1975). The Impact of Malaria on Economic Development: A Case Study. Washington, DC: OPS Publicación Científica. http://bases.bireme.br/cgibin/wxislind.exe/iah/online/?IsisScript=iah/iah.xisandsrc=googleandbase=REPIDISCAa ndlang $=$ pandnextAction $=$ lnkandexprSearch=183732andindexSearch=ID

Cutler, D., W. Fung, M. Kremer, M. Singhal, and T. Vogl (2010). 'Early-life Malaria Exposure and Adult Outcomes: Evidence from Malaria Eradication in India'. American Economic Journal: Applied Economics, 2(2): 72-94 (2010).

Deuchert, E. and C. Wunsch (2013). 'Evaluating Nationwide Health Interventions: Malawi's Insecticide-Treated-Net Distribution Programme'. Journal of the Royal Statistical Society: Series A (Statistics in Society): $\mathrm{n} / \mathrm{a}-\mathrm{n} / \mathrm{a}$.

Dicko, A., I. Sagara, D. Diemert, M. Sogoba, M.B. Niambele, A. Dao, G. Dolo, D. Yalcouye, D.A. Diallo, A. Saul, L.H. Miller, Y.T. Toure, A.D. Klion, O.K. Doumbo (2007). Year-toYear Variation in the Age-specific Incidence of Clinical Malaria in Two Potential Vaccine Testing Sites in Mali with Different Levels of Malaria Transmission Intensity'. American Journal of Tropical Medicine and Hygiene, 77: 1028-33.

Eisele, T.P., J. Keating, M. Littrell, D. Larsen, and K. Macintyre (2009). 'Assessment of Insecticide-Treated Bednet Use among Children and Pregnant Women across 15 Countries Using Standardized National Surveys'. American Journal of Tropical Medicine and Hygiene, 80: 209-14.

Fan, V.Y., D. Duran, R. Silverman, and A. Glassman (2013). 'Performance-based Financing at the Global Fund to Fight AIDS, Tuberculosis and Malaria: An Analysis of Grant Ratings and Funding, 2003-12'. Lancet Global Health, 1: e161-68.

Fernando, D., D. de Silva, R. Carter, K.N. Mendis, and R.A. Wickremasinghe (2006). 'A Randomized, Double-blind, Placebo-controlled, Clinical Trial of the Impact of Malaria Prevention on the Educational Attainment of School Children'. American Journal of Tropical Medicine and Hygiene, 74: 386-93. 
Fernando, S.D., D.M. Gunawardena, M.R. Bandara, D. De Silva, R. Carter, K.N. Mendis, A.R. Wickremasinghe (2003). 'The Impact of Repeated Malaria Attacks on the School Performance of Children'. American Journal of Tropical Medicine and Hygiene, 69: 582-88.

Flaxman, A.D., N. Fullman, M.W. Otten Jr, M. Menon, R.E. Cibulskis, M. Ng, C.J.L. Murray, S.S. Lim (2010). 'Rapid Scaling Up of Insecticide-Treated Bed Net Coverage in Africa and its Relationship with Development Assistance for Health: A Systematic Synthesis of Supply, Distribution, and Household Survey Data'. PLoS medicine, 7(8).

Gallup, J. L., and J. D. Sachs. "The Economic Burden of Malaria." The American Journal of Tropical Medicine and Hygiene 64, no. 1 suppl (January 1, 2001): 85-96.

García-Basteiro, A.L., C. Schwabe, C. Aragon, G. Baltazar, A.M. Rehman, A. Matias, G. Nseng, and I. Kleinschmidt (2011). 'Determinants of Bed Net Use in Children Under Five and Household Bed Net Ownership on Bioko Island, Equatorial Guinea'. Malaria Journal, 10: 179.

Gething, P.W., A.P. Patill, D.L. Smith, C.A. Guerra, I.R.F. Elyazar, G.L. Johnston, A.J. Tatem, and S.I. Hay (2011). 'A New World Malaria Map: Plasmodium Falciparum Endemicity in 2010’. Malaria Journal, 10: 1475-2875.

Gharbi, M., J.A. Flegg, V. Hubert, E. Kendjo, J.E. Metcalf, L. Bertaux, P.J. Guérin, J. Le Bras, and Members of the French National Reference Centre for Imported Malaria Study (2013). 'Longitudinal Study Assessing the Return of Chloroquine Susceptibility of Plasmodium Falciparum in Isolates from Travellers Returning from West and Central Africa, 20002011'. Malaria Journal, 12: 35.

Githinji, S., S. Herbst, T. Kistemann, and A.M. Noor (2010). 'Mosquito Nets in a Rural Area of Western Kenya: Ownership, Use and Quality'. Malaria Journal, 9: 250.

Gomes, M. (1993). 'Economic and Demographic Research on Malaria: A Review of the Evidence'. Social Science and Medicine, 37: 1093-108.

Goodman, C.A., P.G. Coleman, and A.J. Mills (1999). 'Cost-effectiveness of Malaria Control in sub-Saharan Africa'. Lancet, 354: 378-85.

Guerra, C.A., R.E. Howes, A.P. Patil, P.W. Gething, T.P. Van Boeckel, W.H. Temperley, C.W. Kabaria, A.J. Tatem, B.H. Manh, I.R.F. Elyazar, J.K. Baird, R.W. Snow, S.I. Hay (2010). 'The International Limits and Population at Risk of Plasmodium vivax Transmission in 2009'. PLoS Neglegted Tropical Diseases, 4(8): e774.

Guyatt, H.L., S.K. Corlett, T.P. Robinson, S.A. Ochola, and R.W. Snow (2002). 'Malaria Prevention in Highland Kenya: Indoor Residual House-spraying vs. Insecticide-Treated Bednets'. Tropical Medicine and International Health, 7: 298-303.

Hill, J., J. Lines, and M. Rowland (2006). 'Insecticide-Treated Nets'. Advances in Parasitology, 61: 77-128.

Holding, P.A. and R.W. Snow (2001). 'Impact of Plasmodium Falciparum Malaria on Performance and Learning: Review of the Evidence'. In J.G. Breman, A. Egan, G.T. Keusch (eds), The Intolerable Burden Of Malaria: A New Look. At The Numbers: Supplement To Volume 64(1) Of The American Journal Of Tropical Medicine And Hygiene. Northbrook, IL: American Society of Tropical Medicine and Hygiene. http://www.ncbi.nlm.nih.gov/books/NBK2614/

John, C.C., P. Bangirana, J. Byarugaba, R.O. Opoka, R. Idro, A.M. Jurek, B. Wu, M.J. Boivin (2008). 'Cerebral Malaria in Children is Associated with Long-term Cognitive Impairment'. Pediatrics, 122: e92-99. 
Jukes, M.C., M. Pinder, E.L. Grigorenko, H. Baños Smith, G. Walraven, E. Meier Bariau, R.J. Sternberg, L.J Drake, P. Milligan, Y. Bun Cheung, B.M. Greenwood, and D.A.P Bundy (2006). 'Long-term Impact of Malaria Chemoprophylaxis on Cognitive Abilities and Educational Attainment: Follow-up of a Controlled Trial'. PLOS Hub for Clinical Trials, 1(4): e19.

Kilian, A., N. Wijayanandana, and J. Ssekitoleeko (2010). 'Review of Delivery Strategies for Insecticide Treated Mosquito Nets: Are We Ready for the Next Phase of Malaria Control Efforts?' TropIKA. Net, 1.

Kiszewski, A., A. Mellinger, A. Spielman, P. Malaney, S.E. Sachs, J. Sachs (2004). 'A Global Index Representing the Stability of Malaria Transmission'. American Journal of Tropical Medicine and Hygiene, 70: 486-98.

Klayman, D.L. (1985). 'Qinghaosu (Artemisinin): An Antimalarial Drug from China'. Science, 228: 1049-55.

Kolaczinski, J. and K. Hanson (2006). 'Costing the Distribution of Insecticide-Treated Nets: A Review of Cost and Cost-effectiveness Studies to Provide Guidance on Standardization of Costing Methodology'. Malaria Journal, 5: 37.

Krezanoski P.J., A.B. Comfort, and D.H. Hamer (2010). 'Effect of Incentives on InsecticideTreated Bed Net Use in sub-Saharan Africa: A Cluster Randomized Trial in Madagascar'. Malaria Journal, 187. http:/ $/$ www.doaj.org/doaj?currentYear=2013andid=585337andgo=1 andfunc $=$ abstractandf romYear $=$ andtoYear $=$

Kuecken, M., J. Thuilliez, M.-A. Valfort (2013). 'Does Malaria Control Impact Education? A Study of the Global Fund in Africa'. Document de travail du centre d'économie de la Sorbonne 13075. Paris: Pantheon-Sorbonne University.

Laxminarayan, R., I.W. Parry, D.L. Smith, and E.Y. Klein (2010).' Should New Antimalarial Drugs be Subsidized?'. Journal of Health Economics, 29: 445-56.

Leighton, C. and R. Foster (1993). 'Economic Impacts of Malaria in Kenya and Nigeria'. Major Applied Research Paper 6. Bethesda, MA: Abt Associates inc. http://pdf.usaid.gov/pdf docs/pnabs294.pdf

Lengeler, C. (2004). 'Insecticide-Treated Bed Nets and Curtains for Preventing Malaria'. Cochrane Database of Systematic Reviews, 2.

Lin, J.T., J.J. Juliano, and C. Wongsrichanalai (2010). 'Drug-resistant Malaria: The Era of ACT'. Current Infectious Disease Reports, 12: 165-73.

Lucas, A.M. (2010). 'Malaria Eradication and Educational Attainment: Evidence from Paraguay and Sri Lanka'. American Economic Journal: Applied Economics, 2: 46-71.

Lucas, A.M. (2013). 'The Impact of Malaria Eradication on Fertility'. Economic Development and Cultural Change, 61: 607-31.

Mabaso, M.L.H., B. Sharp, and C. Lengeler (2004). 'Historical Review of Malarial Control in Southern African with Emphasis on the Use of Indoor Residual House-spraying'. Tropical Medicine and International Health, 9: 846-56.

Macdonald, G. (1957). The Epidemiology and Control of Malaria. Oxford: Oxford University Press.

Macdonald, G. (1950). The Economic Importance of Malaria in Africa. Unpublished WHO Document.

Marchant, T., D. Schellenberg, R. Nathan, J. Armstrong-Schellenberg, H. Mponda, C. Jones, Y. Sedekia, J. Bruce, K. Hanson (2010). 'Assessment of a National Voucher Scheme to Deliver 
Insecticide-Treated Mosquito Nets to Pregnant Women'. Canadian Medical Association Journal, 182(2): 152-56.

Matovu, F., C. Goodman, V. Wiseman, and W. Mwengee (2009). 'How Equitable is Bed Net Ownership and Utilisation in Tanzania? A Practical Application of the Principles of Horizontal and Vertical Equity'. Malaria Journal, 8: 109.

McCarthy, F.D., H.C. Wolf, and Y. Wu (2000). 'Malaria and Growth'. World Bank Policy Research Working Paper. Washington, DC: World Bank.

Minakawa, N., G.O. Dida, G.O. Sonye, K. Futami, and S. Kaneko (2008). 'Unforeseen Misuses of Bed Nets in Fishing Villages along Lake Victoria'. Malaria Journal, 7: 58.

Morel, C.M., J.A. Lauer, and D.B. Evans (2005). 'Cost Effectiveness Analysis of Strategies to Combat Malaria in Developing Countries’. BMJ 331: 1299.

Mung'ala-Odera, V., R.W. Snow, and C.R.J.C. Newton (2004). 'The Burden of the Neurocognitive Impairment Associated with Plasmodium Falciparum Malaria in subSaharan Africa'. American Journal of Tropical Medicine and Hygiene, 71: 64-70.

Murray, C.J., L.C. Rosenfeld, S.S. Lim, K.G. Andrews, K.J. Foreman, D. Haring, N. Fullman, M. Naghavi, R. Lozano, A.D. Lopez (2012). 'Global Malaria Mortality Between 1980 and 2010: A Systematic Analysis'. Lancet, 379: 413-31.

Nabarro, D.N. and E.M. Tayler (1998). 'The "roll back malaria” campaign'. Science, 280: 2067-68.

Nankabirwa, J., B. Wandera, N. Kiwanuka, S.G. Staedke, M.R. Kamya, S.J. Brooker (2013). 'Asymptomatic Plasmodium Infection and Cognition among Primary Schoolchildren in a High Malaria Transmission Setting in Uganda'. American Journal of Tropical Medicine and Hygiene, 88: 1102-08.

Newman, P. (1970). 'Malaria Control and Population Growth'. Journal of Development Studies, 6: 133-58.

Newman, P. (1965). 'Malaria Eradication and Population Growth: With Special Reference to Ceylon and British Guiana'. Bureau of Public Health Economics Research Series, 10.

Ngoungou, E.B., B. Poudiougou, O. Dulac, A. Dicko, M.P. Boncoeur, A.M. Traoré, D. Coulibaly, M.M. Keita, P.M. Preux, O.K. Doumbo, M. Druet-Cabanac (2007). 'Séquelles neurologiques persistantes dues au paludisme cérébral dans une cohorte d'enfants au Mali'. Revue Neurologique, 163: 583-88.

Onwujekwe, O., K. Hanson, and J. Fox-Rushby (2004). 'Inequalities in Purchase of Mosquito Nets and Willingness to Pay for Insecticide-Treated Nets in Nigeria: Challenges for Malaria Control Interventions. Malaria Journal, 3: 6.

Packard, R.M. (2009). "'Roll Back Malaria, Roll in Development'? Reassessing the Economic Burden of Malaria'. Population and Development Review, 35: 53-87.

Rhee, M., M. Sissoko, S. Perry, W. McFarland, J. Parsonnet, and O. Doumbo (2005). 'Use of Insecticide-Treated Nets (ITNs) Following a Malaria Education Intervention in Piron, Mali: A Control Trial with Systematic Allocation of Households'. Malaria Journal, 4: 35.

Rodrik, D., A. Subramanian, and F. Trebbi (2004). 'Institutions Rule: The Primacy of Institutions over Geography and Integration in Economic Development'. Journal of Economic Growth, 9: 131-65.

Roll Back Malaria (RBM) (2013). 'Global Malaria Action Plan'. http://www.rollbackmalaria.org/gmap/fr/1-3.html (accessed October 2013). 
Sachs, J.D. (2003). Institutions don't rule: direct effects of geography on per capita income. NBER Working Paper 9490. Cambridge, MA: NBER. http://www.nber.org/papers/w9490

Santolamazza, F., (2008). 'Distribution of Knock-down Resistance Mutations in Anopheles Gambiae Molecular Forms in West and West-central Africa'. Malaria Journal, 7: 74.

Seban, J., J. Thuilliez, and V. Herbreteau (2013). 'Possession of Bed Nets in Haut-Katanga (DRC): Prevalence-elastic Behaviour or Performance of Health Care System Delivery?' Health and Place, 24: 275-85.

Shepard, D.S., M.B. Ettling, U. Brinkmann, and R. Sauerborn (1991). The Economic Cost of Malaria in Africa'. Tropical medicine and parasitology: official organ of Deutsche Tropenmedirinische Gesellschaft and of Deutsche Gesellschaft fur Technische Zusammenarbeit (GTZ), 42: 199.

Smith, D.L. and F.E. McKenzie (2004). 'Statics and Dynamics of Malaria Infection in Anopheles Mosquitoes'. Malaria Journal, 3: 13.

Stevens, W., V. Wiseman, J. Ortiz, and D. Chavasse (2005). 'The Costs and Effects of a Nationwide Insecticide-Treated Net Programme: The Case of Malawi'. Malaria Journal, 4: 22.

Tarozzi, A., A. Mahajan, B. Blackburn, D. Kopf, L. Krishnan, and J. Yoong (2011). 'Micro-loans, Insecticide-Treated Bednets and Malaria: Evidence from a Randomized Controlled Trial in Orissa (India)'. ERID Working Paper 104. Durham, NC: Duke University.

Thomson, M.C. J.H. Adiamah, S.J. Connor, M. Jawara, S. Bennett, U. D'Alessandro, M. Quinõnes, P. Langerock, B.M. Greenwood (1995). 'Entomological Evaluation of the Gambia's National Impregnated Bednet Programme'. Annals of Tropical Medicine and Parasitology, 89: 229-41.

Thuilliez, J. (2010a). 'Fever, Malaria and Primary Repetition Rates Amongst School Children in Mali: Combining Demographic and Health Surveys (DHS) with Spatial Malariological Measures'. Social Science and Medicine, 71: 314-23.

Thuilliez, J. (2010b). 'Malaria and Primary Education: A Cross-country Analysis on Repetition and Completion Rates'. Revue d'économie du développement, 23: 127-57.

Thuilliez, J. M.S. Sissoko, O.B. Toure, P. Kamate, J.C. Berthélemy, and O.K. Doumbo (2010). 'Malaria and Primary Education in Mali: A Longitudinal Study in the Village of Donéguébougou'. Social Science and Medicine, 71: 324-34.

Toé, L.P., O. Skovmand, K.R. Dabiré, A. Diabaté, Y. Diallo, T.R. Guiguemdé, J.M.C. Doannio, M. Akogbeto, T. Baldet, and M.-E. Gruénais (2009). 'Decreased Motivation in the Use of Insecticide-Treated Nets in a Malaria Endemic Area in Burkina Faso'. Malaria Journal, 8: 175.

Van Eijk, A.M., J. Hill, V.A. Alegana, V. Kirui, P.W. Gething, F.O. ter Kuile, R.W. Snow (2011). 'Coverage of Malaria Protection in Pregnant Women in sub-Saharan Africa: A Synthesis and Analysis of National Survey Data’. Lancet Infectious Diseases, 11: 190-207.

Wiseman, V., A. Scott, B. McElroy, L. Conteh, and W. Stevens (2007). 'Determinants of Bed Net Use in the Gambia: Implications for Malaria Control'. American Journal of Tropical Medicine and Hygiene, 76: 830-36.

WHO (2012). World Malaria Report: 2012. Geneva: WHO.

Worrall, E., S. Basu, and K. Hanson (2005). 'Is malaria a disease of poverty? A review of the literature'. Tropical Medicine and International Health, 10: 1047-59.

Ye, Y., E. Patton, A. Kilian, S. Dovey, and E. Eckert (2012). 'Can Universal Insecticide-Treated Net Campaigns Achieve Equity in Coverage and Use? The Case of Northern Nigeria'. Malaria Journal, 11: 32. 